\title{
Resolução cirúrgica de pólipo inflamatório em ouvido médio de felino através da técnica de avulsão e tração por abordagem lateral: relato de caso*
}

\section{Surgical resolution of feline middle ear inflammatory polyp by lateral approach traction and avulsion technique: case report}

\author{
Jussara Sampaio Quintela, ${ }^{* *}$ Reginaldo Pereira de Sousa Filho, ${ }^{* * *}$ Keytyanne de Oliveira Sampaio, ${ }^{* * *}$ \\ Lídia Sampaio Batista*****
}

\begin{abstract}
Resumo
O objetivo desse trabalho foi descrever um caso de pólipo inflamatório em ouvido médio de um felino e sua resolução cirúrgica através da avulsão e tração da massa após abordagem lateral. Um felino, fêmea, de 2 anos de idade, foi atendido no Hospital Veterinário Professor Sylvio Barbosa Cardoso, apresentando prurido intenso, dor e secreção fétida em região auricular. Pelo exame físico foi possível observar um nódulo em região de ouvido médio esquerdo. Associado a isso, o animal apresentava "headtilt" (inclinação da cabeça para o lado afetado). Foram solicitados exames hematológicos, radiografia de crânio e citologia da massa. O animal foi encaminhado para cirurgia de extirpação da massa. Foi feita uma incisão na pele sob o canal auditivo vertical palpável. A cartilagem foi liberada até o nível da junção entre as cartilagens auricular e anular. Com o auxílio de um fórceps, o pólipo foi agarrado e delicadamente girado até ser completamente extirpado de sua origem. A cartilagem e o subcutâneo foram fechados com material de sutura monofilamentar 4-0 e a pele foi fechada em um padrão de sutura subdérmica usando o mesmo material. A peça foi encaminhada para exame histopatológico, pelo qual confirmou-se a suspeita de pólipo inflamatório, através da observação de epitélio colunar ciliado. Utilizando a técnica cirúrgica TALA (avulsão e tração após abordagem lateral) foi possível obter melhora do quadro clínico do animal referido, rápida recuperação pós-cirúrgica e sem nenhuma complicação decorrente da técnica. Essa técnica, portanto, se mostrou satisfatória, melhorando significativamente a qualidade de vida do animal.
\end{abstract}

Palavras-chave: cirurgia, conduto auditivo, histopatológico, inclinação da cabeça, radiografia.

\begin{abstract}
The aim of this study was to describe a case of inflammatory polyp in the middle ear of a cat and its surgical resolution through avulsion and mass traction after lateral approach. A female feline, two year old, was admitted at the Hospital Veterinário Professor Sylvio Barbosa Cardoso, presenting intense itching, pain and fetid discharge in the ear region. Physical examination revealed a nodule in the left middle ear region. Associated with this, the animal presented head tilt (inclination of the head to the affected side). Hematological examinations, skull radiography and mass cytology were requested. The animal was referred for polyp removal surgery. A skin incision was made under the palpable vertical ear canal. The cartilage was released to the level of the junction between the auricular and annular cartilages. With the help of a forceps, the polyp was grasped and gently rotated until completely removed from its origin. The cartilage and subcutaneous tissue were closed with 4-0 monofilament suture material and the skin was closed in a subdermal suture pattern using the same material. The piece was referred for histopathological examination, which confirmed the suspicion of inflammatory polyp by observing ciliated columnar epithelium. Using the TALA surgical technique (avulsion and traction after lateral approach) it was possible to obtain improvement of the clinical 3 picture of the referred animal, rapid postoperative recovery and without any complications resulting from the technique. This technique therefore proves satisfying, significantly improving the quality of life of the animal
\end{abstract}

Keywords: ear canal, headtilt, histopathological,radiography, surgery.

\section{Introdução}

Pólipos inflamatórios em ouvido médio são conhecidos por serem os tumores benignos mais diagnosticados na espécie felina (Fan e Lorimier, 2004). São massas benignas que podem se originar no ouvido médio ou tuba de Eustáquio. Estes podem crescer, romper a membrana timpânica e se estender até o ouvido externo, ou podem ainda alcançar a nasofaringe. Acredita-se que a origem dos pólipos esteja relacionada a inflamações crônicas do ouvido médio/interno ou do trato respiratório inferior, contudo

*Recebido em 20 de setembro de 2019 e aceito em 10 de fevereiro de 2020.

**Médica Veterinária autônoma; Fortaleza; CE- Brasil. Autor para correspondência: Jussara.sampaio@yahoo.com.br.

***Universidade Estadual do Ceará; Faculdade de Veterinária; Fortaleza; CE-Brasil.

****Médica Veterinária autônoma; Fortaleza; CE- Brasil.

****Universidade Estadual do Ceará; Faculdade de Veterinária; Fortaleza; CE-Brasil. 
essa hipótese ainda não está bem esclarecida. Gatos jovens são mais frequentemente acometidos (Harvey e Goldschmidt, 1978; Lorenzi et al, 2005; Greci e Mortellaro, 2016).

Dependendo da localização do pólipo, os sinais clínicos podem variar, podendo estar presente desde sinais respiratórios até sinais vestibulares. Os sinais das vias aéreas superiores incluem disfagia, estertor, corrimento nasal, espirros, alteração da voz e dispneia. Outros sinais como inclinação da cabeça, tremores, nistagmo, Síndrome de Horner e secreções auriculares estão relacionados ao ouvido médio e sistema vestibular (Fan e Lorimier, 2004; Greci et al, 2014).

O diagnóstico é feito por meio do histórico, exame físico, exames complementares como exames de imagem (radiografia, tomografia computadorizada), citologia e histopatologia da massa, sendo o diagnóstico confirmatório dado pelo histopatológico, com a observação de epitélio estratificado ciliado (Lorenzi et al, 2005; Greci et al, 2014).

O tratamento consiste na ressecção cirúrgica da massa. Geralmente há baixo índice de recorrência (Harvey e Goldschmidt, 1978).

O objetivo desse trabalho é descrever um caso de pólipo inflamatório em ouvido médio de um felino, bem como a resolução cirúrgica do caso, utilizando a técnica de avulsão e tração da massa após abordagem lateral.

\section{Relato de caso}

Um felino, fêmea, de raça Siamês, com 2 anos de idade, deu entrada no XXXX, apresentando prurido intenso, dor e secreção em região auricular. No exame físico o animal apresentava dor a palpação do ouvido esquerdo. Através da inspeção e de exame otoscópico foi possível detectar, além da secreção, uma massa de coloração avermelhada em região de ouvido médio esquerdo (Figura 1). O palato mole foi inspecionado para visualização da faringe, onde não foram observados pólipos nasofaríngeos.

As alterações neurológicas observadas foram "headtilt"(inclinação da cabeça para o lado afetado) e nistagmo horizontal (sendo sugestivo de nistagmo fisiológico para a raça).

Foram solicitados exames hematológicos, sendo eles hemograma completo e dosagens bioquímicas (ureia, creatinina,

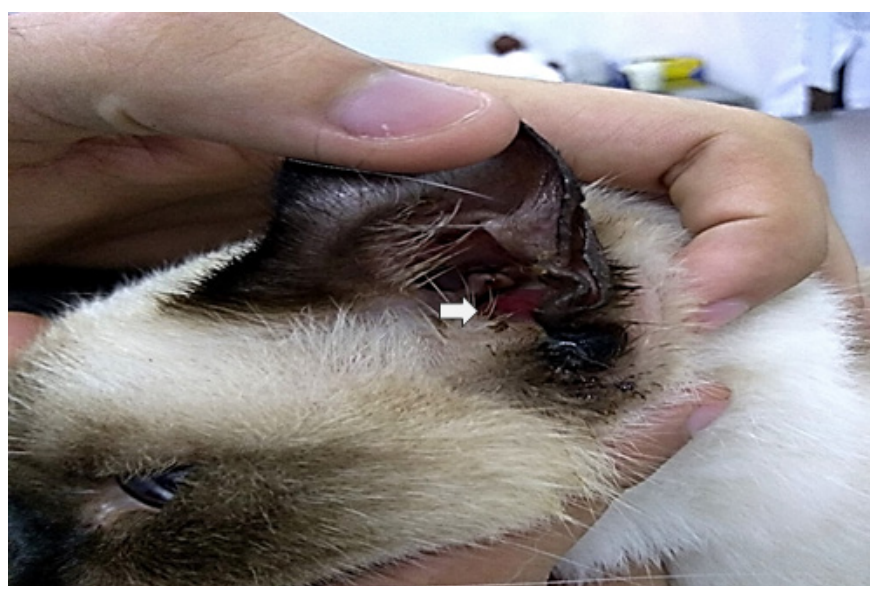

Figura 1: Porção externa de pólipo, protusa em canal auditivo externo esquerdo (seta branca)
ALT e FA); radiografia de crânio e citologia. A radiografia de crânio foi solicitada com a finalidade de se observar a integridade da bula timpânica e demais estruturas adjacentes a massa. A citologia da massa foi realizada afim de se obter informações acerca do tipo de células envolvidas na neoformação, bem como seu aspecto benigno ou maligno. O resultado dos exames hematológicos se encontrava dentro do intervalo de referência para a espécie. A radiografia de crânio não evidenciou coleções de líquido ou massa em região de bula timpânica, sendo a massa visualizada apenas em região de conduto auditivo esquerdo (Figura 2).

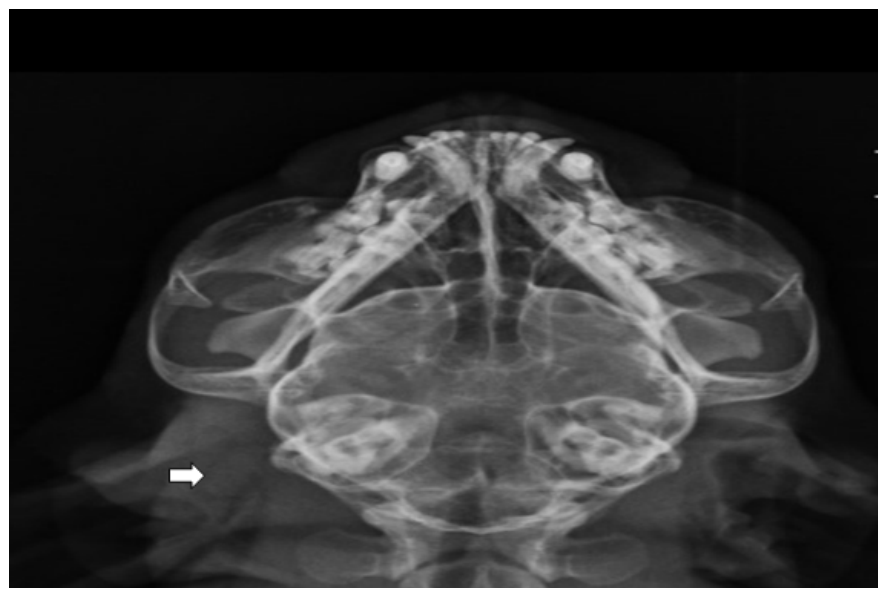

Figura 2: Radiografia dorsoventral indicando nódulo em conduto auditivo esquerdo (seta branca)

A observação total do conduto auditivo não foi possível devido ao aumento de volume de partes moles ao seu redor. A citologia coletada por punção não aspirativa revelou moderado processo inflamatório com presença de neutrófilos íntegros e degenerados, linfócitos e raros macrófagos. Sob análise histopatológica, ao exame macroscópico, o fragmento era pardo, medindo $1,2 \times 0,8 \times 0,3 \mathrm{~cm}$ (Figura 3).

Ao corte, se mostrou firme, compacto e branco. Pela microscopia foi possível constatar proliferação polipoide revestida externamente por epitélio colunar ciliado. Internamente, observou-se intenso infiltrado inflamatório de linfócitos, plasmócitos, macrófagos neutrófilos, além de pseudoglândulas formadas contendo material mucinoso em seu interior e no tecido adjacente. Após o resultado dos exames, o animal foi encaminhado para extirpação da massa cirurgicamente.

A técnica utilizada foi de acordo com Janssens et al, 2017. Após a preparação asséptica do sítio cirúrgico, foi feita uma incisão na pele em direção dorso-ventral sobre o canal auditivo vertical palpável, iniciando-se crânio-ventralmente ao trago por aproximadamente $2,5 \mathrm{~cm}$. Os tecidos subcutâneos foram dissecados com cuidado para liberação da cartilagem do canal auditivo vertical até o nível da junção entre as cartilagens auricular e anular, refletindo a glândula parótida. Uma incisão vertical foi feita ventralmente a dorsalmente na cartilagem auricular logo acima desta junção com bisturi. Foram colocadas suturas em ambos os lados da incisão na cartilagem do canal auditivo com material fino de sutura monofilamentar para aumentar a visualização e evitar danos à cartilagem (Figura 4). 


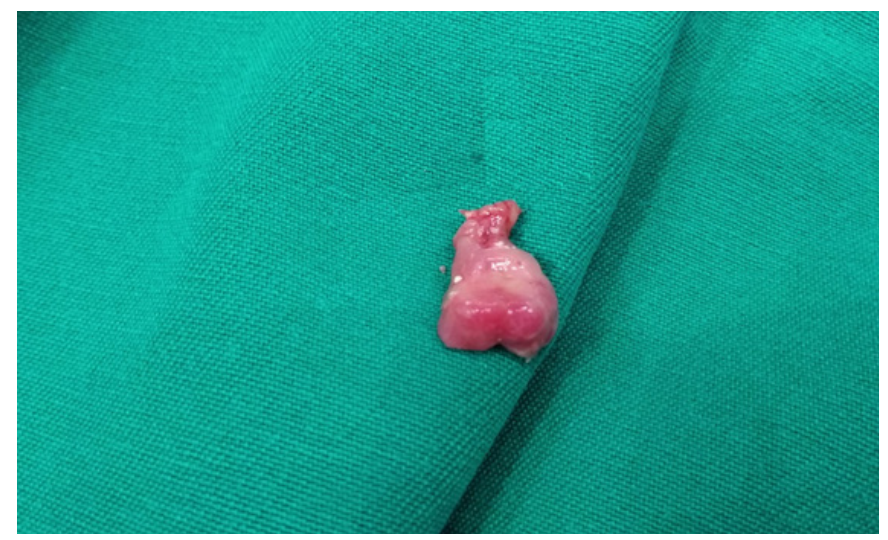

Figura 3: Pólipo ressecado de ouvido médio de felino, de aparência parda medindo $1,2 \times 0,8 \times 0,3 \mathrm{~cm}$.

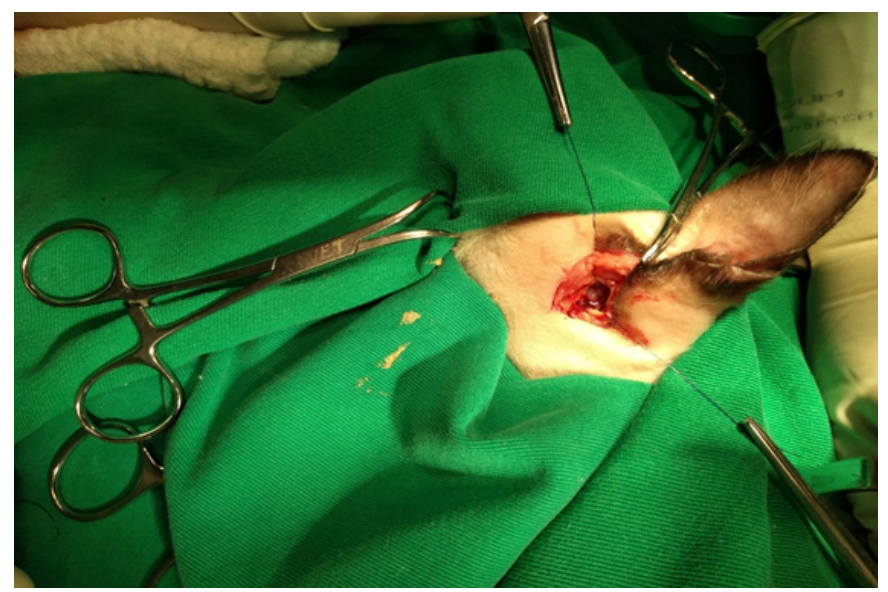

Figura 4: Acesso lateral do conduto auditivo médio, para exérese de pólipo localizado em ouvido médio.

Um pequeno fórceps hemostático curvo foi então introduzido fechado no canal auditivo, seguindo meticulosamente a direção do canal auditivo horizontal até que o pólipo fosse encontrado. A pinça foi então aberta e avançou mais profundamente sobre o pólipo até que pudesse ser agarrada o mais próximo possível do meato ósseo. A pinça foi gentilmente girada para que o pólipo fosse arrancado de sua origem. A cavidade do ouvido médio foi lavada com solução salina morna e com uma pequena cureta o meato ósseo e o lado mais lateral da cavidade timpânica foi inspecionado para verificar se havia tecido inflamatório adicional. A cartilagem do canal auditivo foi fechada com material de sutura absorvível monofilamentar 4-0 em um padrão interrompido. Quatro suturas foram suficientes. O subcutâneo foi fechado em um padrão contínuo com material monofilamentar absorvível 4-0 e a pele foi fechada em um padrão de sutura subdérmica usando o mesmo material (Figura 5).

Para o pós-operatório foram prescritos terapia com prednisolona na dose anti-inflamatória $(1 \mathrm{mg} / \mathrm{kg} / \mathrm{SID} / \mathrm{VO})$ por três dias, amoxicilina com clavulanato $(15 \mathrm{mg} / \mathrm{kg} / \mathrm{BID} / \mathrm{VO})$ por sete dias e tramadol ( $1 \mathrm{mg} / \mathrm{kg}$ BID/VO) por 5 dias.

A peça foi encaminhada para exame histopatológico, para confirmação do diagnóstico de pólipo inflamatório.

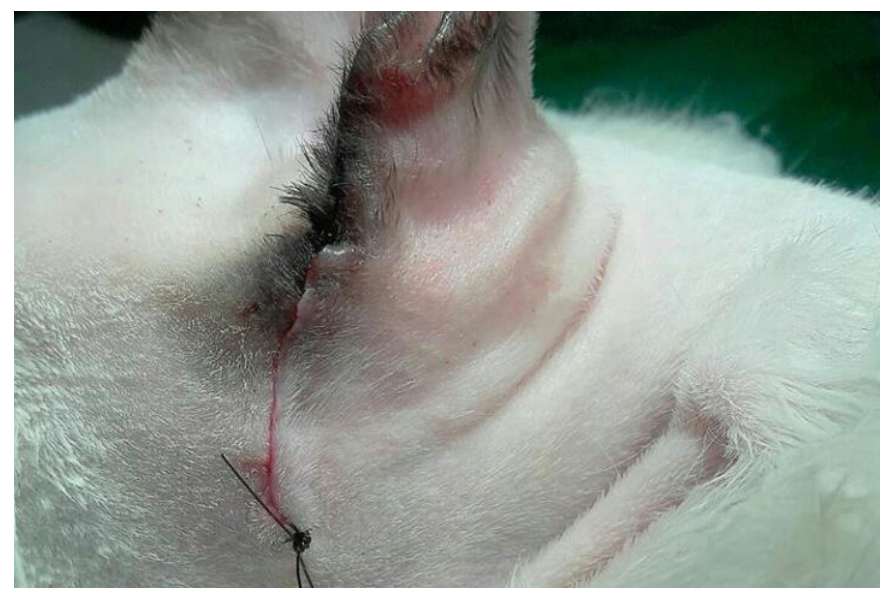

Figura 5: Aspecto final da cirurgia de avulsão e tração por acesso lateral, no pós operatório imediato, demonstrando o fechamento da pele em padrão de sutura subdérmica.

\section{Discussão}

O relato descreve o caso de um felino da raça siamês e idade de 2 anos, se assemelhando aos dados encontrados na literatura, onde animais jovens e de raças puras incluindo a raça siamês são ditos como os mais acometidos (Anderson et al, 2000; Veir et al, 2002; Janssens et al, 2017).

As características observadas ao exame histopatológico da peça foram compatíveis com pólipo inflamatório auricular, e são consistentes com os resultados descritos pela literatura (Harvey e Goldschmidt, 1978; Anderson et al, 2000; Colcuc et al, 2002; Blutke et al, 2010).

Embora sinais relacionados a otite (otorréia, prurido) e ao sistema respiratório sejam mais frequentemente encontrados em casos de pólipos auriculares e nasofaringeos respectivamente, sinais vestibulares também podem estar presentes, como mostra o presente relato (Veir et al, 2002; Macphail et al, 2007;Blutke et al, 2010;Colcuc et al, 2011;Greci et al, 2014;Janssens et al, 2017). Apesar de não ter se evidenciado no momento da radiografia comprometimento de estruturas mais internas do ouvido, o animal apresentava "headtilt", sugerindo que estruturas do sistema vestibular poderiam ter sido afetadas, de forma a comprometer a transmissão dos impulsos nervosos resultantes da estimulação de células neuroreceptoras no ouvido interno, responsáveis por regular a postura do corpo e cabeça.

Os diferentes procedimentos cirúrgicos para tratamento de pólipo em ouvido médio são amplamente discutidos na literatura. Enquanto alguns autores recomendam a avulsão e tração do pólipo, outros preferem métodos mais invasivos, como a osteotomia da bula lateral ou ventral (Williams e White, 1992; Macphail et al, 2007; Colcuc et al, 2011; Janssens et al, 2017). Em um trabalho publicado, 30 gatos com pólipos foram tratados pela técnica cirúrgica de avulsão e tração (Anderson et al, 2000). O acompanhamento do pós-operatório foi possível em 22 casos, destes, nove desenvolveram recidivas. Acredita-se que as recidivas que ocorrem mais frequentemente nessa técnica esteja relacionada com resquícios de tecido inflamatório deixados pelo procedimento, além de restos de secreções como muco e pus. Outros autores defendem a osteotomia da bula ventral, por permitir uma minuciosa curetagem do tecido inflamatório, 
adequada drenagem de líquido e material envolvidos na inflamação, permitindo ainda boa entrada de ar para o ouvido médio. A literatura relata que o maior fluxo de oxigênio e menor quantidade de muco no ouvido médio, auxiliam na reversão da metaplasia (Colcuc et al, 2011). Contudo, a técnica deve ser cuidadosamente executada, tendo em vista o risco potencial de atingir fibras simpáticas e estruturas vestibulares adjacentes a cavidade timpânica. Portanto, algumas complicações podem surgir, como Síndrome de Horner e vestibular, lesão do nervo hipoglosso e paralisia do nervo facial (Williams e White, 1992; Donnelly e Tillson, 2004; Fossum, 2014).

Em um experimento com 13 felinos tratados pelo VBO (osteotomia da bula ventral), em apenas um o pólipo recorreu, no entanto, o artigo não relata se houve complicações (Veir et al, 2002).

Uma vez que há chances reais de ocorrer complicações, alguns autores optam pela técnica mais simples e conservadora no primeiro momento, a técnica por tração (TA). Caso haja recidivas e comprometimento da bula timpânica, outras técnicas como a osteotomia da bula ventral são então consideradas (Veir et al, 2002; Janssens et al, 2017). Segundo Veir et al (2002), as recorrências com a TA sozinha ocorrem principalmente quando há comprometimento da bula. Um estudo utilizando a técnica de avulsão e tração após abordagem lateral (TALA) mostrou que a técnica pode ser bastante eficaz, tendo baixas taxas de recidivas, onde dos 62 animais submetidos a técnica, apenas sete apresentaram Síndrome de Horner e dois animais apresentaram paralisia do nervo facial. A maioria dos tutores $(75,8 \%)$ se mostraram satisfeitos, relatando que seus animais se recuperaram totalmente. A recorrência dos pólipos ocorreu em quatro casos confirmados, após no mínimo 12 meses de cirurgia (Janssens et al, 2017). Dessa forma, como não havia evidências de comprometimento da bula timpânica no presente relato, tendo em vista os bons resultados descritos por Janssens et al (2017), com menores chances de complicações, e por se tratar de uma técnica simples e rápida, optou-se no primeiro momento pela técnica de avulsão e tração da massa após

\section{Referências}

ANDERSON, D.M.; ROBINSON R.K.; WHITE R.A.S. Management of inflammatory polyps in 37 cats. Veterinary Record. v.147, n.24, p.684-687, 2000.

BLUTKE, A.; PARZEFALL, B.; STEGER, A.; GOEDDE, T.; HERMANNS, W. Inflammatory polyp in the middle ear of a dog: a case report. Veterinarni Medicina. v.55, n.6, p.289-293, 2010.

COLCUC M.; DEGASPERI, B.; ALTON, K. Feline ear polyps: Two case reports and a model for pathogenesis - chronic otitis media with effusion. Ear Nose and Throat. v.21, n.1, p.37-45, 2011.

DONNELLY, K.E.; TILLSON, D.M. Feline inflammatory polyps and ventral bulla osteotomy. Compendium on Continuing Education for the Practising Veterinarian, North American Edition. v.26, n.6, p.446-453, 2004.

FAN, T.M.; LORIMIER, L.P. Inflammatory polyps and aural neoplasia. Veterinary Clinics of North America Small Animal Practice, v.34, n.2, p.489-509, 2004.

FOSSUM, T.W. Cirurgia do ouvido. In: FOSSUM, T.W. Cirurgia de pequenos animais. 4 ed. Rio de Janeiro: Elsevier, 2014, p. 329-345. abordagem lateral (TALA) que possibilitou melhor visualização do pólipo e da região acometida por ele, bem como facilitou a sua completa excisão. O transoperatório transcorreu sem nenhuma complicação cirúrgica. Decorridos uma semana da cirurgia, o animal não apresentava mais prurido e secreções auriculares, embora ainda apresentasse uma ligeira inclinação da cabeça. Conforme descrito na literatura, a resolução completa do "headtilt" ocorre gradativamente (Macphail et al, 2007).

Em um estudo em que felinos com pólipos foram submetidos a terapia com corticosteroide após a cirurgia, Anderson et al (2000) sugeriu que o uso da prednisolona no pós-operatório previne a recorrência da massa. Dessa forma, a prednisolona foi prescrita por mais sete dias para o felino do presente relato, afim de se evitar recidivas. Após 50 dias de pós-operatório foi realizada uma nova radiografia de crânio afim de avaliar quanto a possíveis recidivas ou presença de restos de tecido inflamatório deixados pelo procedimento. Não foram visualizadas quaisquer estruturas semelhantes a pólipos em região de conduto auditivo e bula timpânica. A bula timpânica apresentava-se integra, sem evidências de conteúdo líquido. Embora o animal continuasse com inclinação da cabeça, o grau de inclinação estava menor, demonstrando melhora no decorrer dos dias. O animal continuava sem apresentar sinais de dor, prurido ou secreções.

\section{Conclusão}

A técnica de avulsão e tração após abordagem lateral utilizada nesse caso possibilitou melhora do quadro clínico do animal, rápida recuperação pós-cirúrgica e nenhuma complicação decorrente da técnica. A maioria dos sinais clínicos foram solucionados. Houve redução no grau de inclinação da cabeça do felino, contudo, torna-se necessário um acompanhamento mais prolongado para verificar se haverá resolução completa do "headtilt". Por fim, a TALA (técnica de avulsão e tração da massa após abordagem lateral) se mostrou satisfatória, melhorando significativamente a qualidade de vida do animal.

GRECI V.; MORTELLARO, C.M. Management of Otic and Nasopharyngeal, and Nasal Polyps in Cats and Dogs. Veterinary Clinics of North America: Small Animal Practice, v.46, n.4, p.643661, 2016.

GRECI V.; VERNIA, E.; MORTELLARO, C.M. Perendoscopictrans-tympanictraction for the management of feline aural inflammatory polyps: a case review of 37 cats. Journal of Feline Medicine and Surgery, v.16, n.8, p.645-50, 2014.

HARVEY, C.E.; GOLDSCHMIDT, M.H. Inflammatory polypoid growths in the ear canal of cats. Journal of Small Animal Practice,v.19, n.1-12, p.669-677, 1978.

JANSSENS, S.D.; HAAGSMAN, A.N.; HAAR, G.T. Middle ear polyps: results of traction avulsion after a lateral approach to the ear canal in 62 cats (2004-2014). Journal of Feline Medicine and Surgery, v.19, n.8, p.803-808, 2017.

LORENZI, D.D.; BONFANTI, U.; MASSERDOTTI, C.;

TRANQUILO, M. Fine-needle biopsy of external ear canal masses in the cat: cytologic results and histologic correlations in 27 cases. Veterinary clinical pathology, v.34, n.2, p.100-5, 2005. 
MACPHAIL, C.M.; INNOCENTI, C.M.; KUDNIG, S.T.; VEIR, J.K.; LAPPIN, M.R. Atypical manifestations of feline inflammatory polyps in three cats. Journal of Feline Medicine and Surgery, v.9, n.3, p.219-225, 2007.

VEIR, J.K.; LAPPIN, M.R.; FOLEY, J.E.; GETZY, D.M. Feline inflammatory polyps: historical, clinical, and PCR findings for feline calicivirus and feline herpes virus- 1 in 28 cases. Journal of Feline Medicine and Surgery, v.4, n.4, p.195-9, 2002.
WILLIAMS, J.M.; WHITE, A.S. Total ear canal ablation combined with lateral bullaosteotornv in J the cat. Journal of Small Animal Practice, v.33, n.5, p.225-227, 1992. 